Siot-mas poscibly prore of sufficient interest for pablica lon, even though the practice recorded, that of leaving the ving of the limb, to the patient's "feeling of animal conceiousmess", after the fashion of Abernethy's monkey, be not in accordance with the "rules laid down bJ the warmest promoters of excision".

P.S.-The case of "successful excision of the kneejoint", reported in the Association Jounsal of August 4th, 1854, has been honoured by a far from complimentary critical notice in the Edinburgh Medical and Surgical Journal of October 1854. It will not perhaps be uninteresting to the authorities of that periodical to learn that their predictions, as to permanency of cure, have not been realised; as the boy, now npwards of twenty months after the operation (as was reported in Mr. Butcher's excellent monoprap in a recent number of the Dublin Quarterly Journal of Iedical Science, continues in the enjoyment of better health, and has the use of a firmly anchylosed serviceable limb. The prospect of an operation of "settled inexpediency" triumphing over unmerited obloquy, and the admission of its right "to a fair and properly conducted trial", must prove very gratifying to $\mathrm{Mr}$. Jones and others, who have had as yet but to deal with "bare statements and preconceired opinions".

King's Iynn, Juuc Jth, 1855.

\section{CASE OF SCIRRHUS OF THE PANCREAS AND STOMACH.}

By JOHN S. BARTRUM, Esq., F.R.C.S., Surgeon to the Bath General Hospital.

[Read at the Quarterly Neeting of the Bath and Bristol Branch, on DIarch 29th, 1855.]

TuE case of scirrhous pancreas now laid before the society presents no features of special interest, except in a negative sense, but will serve to elicit the experience of those members whose opportunities are more abundant or observation more correct.

CASE. A. M., aged 52 years, married, but never pregnant, for several years had suffered from attacks apparently of debility, accompanied by continuous epigastric pain, without tenderness on pressure, vomiting or swelling. These attacks quickly subsided under change of air, tonics, and sedatives, and she resumed her ordinary active duties. By slow degrees, her skin became slightly yellow and muddy; she lost power and flesh; the attacks of gastrodynia becoming more severe and less amenable to remedies. The sensation was described as leing not so much pain as painful exhaustion, requiring and receiving immediate relief from nourishment. In the spring of 1854 , for a while the most painful spot was immediately below the edge of the liver at the edge of the false ribs, where a circumscribed spot an inch square was tender on deep pressure; this was ascribed to irritation or inflammation of the pylorus or duodenum, as the motions were not properly coloured with bile. There was no increase of size or general tenderness, and the pain extended through to the back. The catamenia were regular, till shortly before death.

The digestive functions appeared to go on naturally ; a large amount of nourishment given in small quantities was daily digested; the most troublesome and distressing symptom was incontrollable flatulence from the stomach, not dependent on the time or kind of food. The bowels were mather irregular and irritable, otherwise the motions were of natural consistence and colour, except when deficient in bile. On no occasion was anything resembling fat or oily matter detected, even while taking cod-liver oil, though carefully watched for. Vomiting was rare, and then it appeared to arise from distension by wind; the matter romited had never any blackened or other appearance leading to a suspicion of cancer of the stomach. The urine was natural. After a while, the right thigh and leg became swollen, the pain extending in a line from the right hypochondrium to the right groin; the femoral vein be- came tender in sereral perts of its conrse, and the thigh more strollen. The abdomen became tympanitic, and doath took place from inanition, notwithstanding tho large quantity of nourishment continually taken, and apparently digested.

The epigastric region was in the later stages somewhat prominent, but not markedly 80 ; there was indistinct dullness; it being not so resonant as the other tympanitic parte of the abdomen; at one period of the disease a hardnees was discernible in the pyloric region, the liver at that time appearing to extend below its natural limits.

On examination after death, the head of the pancreas was enlarged to the size of a goose egg, by the deposit in its tissue of white scirrhous cancer; there were similar deposits in the smaller end, and in some neighbouring absorbent glands. The pancreas was not adherent to the duodenum or liver. The pyloric end of the stomach, especially at its larger curvature, was much thickened by the deposit of cancer, apparently colloid, without any abrasion of the surface, but covered with the dark black slimy mucus so often ejected in cases of cancer of the stomach; this deposit ceased abruptly at the pylorus. The duodenum appeared quite healthy. The liver, spleen, and other abdominal organs, werc healthy. The thorax was not examined.

REMARES. The question that arises in this case is, which organ was probably the first diseased, pancreas or stomach? My impression is, that the pancreas was the first disordered; or, more probably, the deposit took place simultaneously; but the failure of the gland in its proper functions had the greatest share in the debility and inanition, which alone marked the case till some weeks previous to death.

Bath, Nay 1855.

\section{MALFORMATION OF THE OESOPHAGUS.} By FREDFRICK MASON, Esq.

[Read at the Quarterly Meeting of the Bath and Bristol Branch, on March 29th, 1855.]

Os the 17th December 1854, Mrs. - was delivered of her second child. It was less than the average size, and without the usual development of fat, but was otherwise apparently well formed; and although it was not a strong child, there appeared no probability of a speedy termination to its life.

On the following day, I noticed that the breathing was accompanied by loud mucous râle from a collection of mucus in the pharynx; and the nurse stated that the child frequently vomited a quantity of thick stringy stuff (mucus). It passed meconium once.

December 19th. The nurse complained that the vomiting continued, and that the infant did not appear able to swallow anything; and although it sucked, the milk did not pass lower than the upper edge of the sternum: and when it reached this place, the child became uneasy, until it had ejected the whole. It would then suck again.

December 20th. The child appeared very hungry, and manifested great eagerness for the breast; but the milk was returned immediately. I now suspected some malformation of the osophagus that prevented the passage of the food to the stomach; and as the infant was evidently getting weaker and wasting rapidly, I recommended small injections of milk and water: these were retained, and on two occasions returned some time after, being thrown up stained the colour of meconium.

During the succeeding days, the child continued to waste, at the same time exhibiting the greatest desire for the breast; but, in consequence of the milk being always returned so quickly, the mother discontinued the attempt to suckle.

The infant died on the 24th December, haring lived seven days.

I made a post mortem examination the next day. The 